\title{
Ligustrazine induces the colorectal cancer cells apoptosis via p53-dependent mitochondrial pathway and cell cycle arrest at the G0/G1 phase
}

\author{
Yaoyao Bian ${ }^{1,2 \#}$, Lili Yang ${ }^{3,4 \#}$, Wei Sheng ${ }^{5 \#}$, Zhengjun $\mathrm{Li}^{6} \wedge$, Yuying $\mathrm{Xu}^{1,2}$, Wenlin $\mathrm{Li}^{4} \wedge$, Li Zeng ${ }^{3,4} \wedge$ \\ ${ }^{1}$ School of Nursing, Nanjing University of Chinese Medicine, Nanjing, China; ${ }^{2}$ TCM Nursing Intervention Laboratory of Chronic Disease Key \\ Laboratory, Nanjing, China; ${ }^{3}$ School of First Clinical Medicine, Nanjing University of Chinese Medicine, Nanjing, China; ${ }^{4}$ Jingwen Library, Nanjing \\ University of Chinese Medicine, Nanjing, China; ${ }^{5}$ Department of Cardiology, Nantong Hospital of Traditional Chinese Medicine, Nantong, China; \\ ${ }^{6}$ College of Health Economics Management, Nanjing University of Chinese Medicine, Nanjing, China \\ Contributions: (I) Conception and design: Y Bian, L Yang; (II) Administrative support: W Li, L Zeng; (III) Provision of study materials or patients: Y \\ Bian, L Yang; (IV) Collection and assembly of data: Y Xu; (V) Data analysis and interpretation: W Sheng, Z Li; (VI) Manuscript writing: All authors; \\ (VII) Final approval of manuscript: All authors. \\ "These authors contributed equally to this work. \\ Correspondence to: Li Zeng. School of First Clinical Medicine and Jingwen Library, Nanjing University of Chinese Medicine, No. 138 Xianlin Road, \\ Nanjing 210023, China. Email: zengbingli@njucm.edu.cn.
}

Background Ligustrazine, active ingredients extracted from the natural herb Ligusticum Chuanxiong Hort, has promising anti-tumor properties on tumor cell lines. However, the potential anti-tumor activity of ligustrazine on colorectal cancer (CRC) cells and the molecular mechanisms have not been elucidated. In this study, we explored the critical functions of ligustrazine on SW480 and CT26 cells at cellular levels.

Methods: CCK-8 assay was performed to analyze the cell viability. Flow cytometry analysis was applied to study cell apoptosis and cell cycle. The expressions of cell apoptosis and cell cycle-associated proteins were conducted by western blot and qRT-PCR analysis.

Results: Ligustrazine showed significant inhibitory effects on the proliferation of SW480 and CT26 cells. Ligustrazine induced cell apoptosis was associated with the up-regulation of pro-apoptotic protein and the down-regulation of anti-apoptotic protein in an activated mitochondrial-dependent pathway. And it indicated that ligustrazine induced cell cycle arrest by changing the cell cycle distribution, which leads to cell cycle arrest at the G0/G1 phase. Besides, the ligustrazine-induced cell apoptosis and cell cycle arrest were markedly reversed by pifithrin- $\alpha$ (p53 inhibitor), which suggested that ligustrazine-induced cell apoptosis was achieved by regulating p53-dependent mitochondrial pathway and cell cycle arrest at the G0/G1 phase.

Conclusions: These findings demonstrated that ligustrazine could induce SW480 and CT26 cells apoptosis via a p53-dependent mitochondrial pathway and cell cycle arrest at the G0/G1 phase. Ligustrazine may serve as a potential anti-cancer agent for CRC.

Keywords: Ligustrazine; colorectal cancer (CRC); apoptosis; mitochondrial pathway; p53

Submitted Jan 27, 2020. Accepted for publication Sep 30, 2020.

doi: $10.21037 /$ apm-20-288

View this article at: http://dx.doi.org/10.21037/apm-20-288

^ Yaoyao Bian: ORCID: 0000-0002-9968-2501; Lili Yang: ORCID: 0000-0001-5220-3094; Zhengjun Li: ORCID: 0000-0001-8208-3898; Wenlin Li: ORCID: 0000-0002-7105-2743; Li Zeng: ORCID: 0000-0002-9095-9439. 


\section{Introduction}

Colorectal cancer (CRC) is one of the major clinical concerns worldwide. It ranks as the 3 rd most common cancer and the fourth leading cause of cancer death according to the Global Burden of Disease (GBD) study (1). Its incidence rate indicates an upward trend and the age of onset is a younger trend. It is estimated that 2.2 million new cases are diagnosed with CRC and 1.1 million cases die of CRC by 2030 (2). The global costs for CRC diagnosis and treatment rise to 100 billion dollars (3). It brings out a huge burden on individuals and families, as well as the whole society. However, there is no effective treatment for CRC until now.

Notably, a variety of evidence (4-6) showed that natural products and herbal extract had unique advantages and limited side effects either on improving the cancer microenvironment or enhancing the anti-cancer effect in treating cancers. Ligustrazine $(\mathrm{C} 8 \mathrm{H} 12 \mathrm{~N} 2)$ is the active ingredient that is extracted from the root of herbal Ligusticum Chuanxiong Hort (Umbelliferae). It has promising activities with lots of pharmacology characteristics such as anti-tumor effect, inhibiting angiogenesis, and reversing multidrug resistance in the treatment of various cancers both in vivo and in vitro (7-10). However, the underlying mechanism of ligustrazine on treating CRC has not been entirely elucidated.

Nowadays, cell apoptosis has gained many attentions on the antitumor effect. Cell apoptosis is a gene controlled multi-cells-independent death process, which is a vital mechanism to maintain homeostasis (11). The balance between cellular proliferation and apoptosis is very important in the occurrence, development, and metastasis of tumor cells. During the cell apoptosis process, the mitochondrial pathway plays a crucial role in signal transduction. In this paper, we tried to elucidate the critical contribution of ligustrazine on inhibiting CRC cell proliferation and inducing CRC cell apoptosis through the mitochondrial pathway at the cellular level. We present the following article in accordance with the MDAR checklist (available at http://dx.doi.org/10.21037/apm-20-288).

\section{Methods}

\section{Reagents and antibodies}

Ligustrazine (C8H12N2, purity $>98 \%$ ) was provided by Tokyo Chemical Industry (Japan), which is dissolved in dimethyl sulfoxide (Sigma-Aldrich, USA) to a proper concentration. DMEM medium, 0.25\% trypsin (Gibco, USA), fetal bovine serum (Every Green, China), penicillin and streptomycin (Sigma-Aldrich, USA), FITC Annexin V Apoptosis Detection Kit and 7-AAD (BD Biosciences, USA), CCK-8 (Dojindo, Japan), DAPI (Beyotime, China), TRIzol reagent (Invitrogen, USA), First Stand cDNA Synthesis Kit (Thermo Fisher Scientific, USA), and UltraSYBR One-Step RTqPCR Kit (Cwbio, China) were used. All primers were purchased from GeneScript (China). Primary antibodies against, p27 (sc-71813), CDK2 (sc-53219), Cyclin D1 (sc-56302), p53 (sc-71819), Bax (sc-20067), Bcl-2 (sc56015), cleaved PARP (sc-56196) and $\beta$-actin were all purchased from Santa Cruz Biotechnology (USA) and cleaved caspase-3 [9661] and cleaved caspase-9 (9505 and 9509) were provided by Cell signaling Technology (USA). The p53 inhibitor (PFT- $\alpha$, s2929) was got from Selleck Chemicals (USA).

\section{Cell lines and cell culture}

Human CRC cell line SW480, mouse CRC cell line CT26, and normal colon cells (CCD841) were purchased from Nanjing Jinyibai Biotechnology Co., Ltd. The cells were maintained in DMEM medium supplemented with $10 \%$ fetal bovine serum, $100 \mathrm{U} / \mathrm{mL}$ penicillin, and $100 \mu \mathrm{g} / \mathrm{mL}$ streptomycin at $37{ }^{\circ} \mathrm{C}$, and incubated in a humidified $5 \%$ $\mathrm{CO}_{2}$ atmosphere.

\section{Cell viability assay}

SW480, CT26, and CCD841 cells $\left(2 \times 10^{4}\right)$ were cultured in 96-well plates and allowed to attach for $12 \mathrm{~h}$. Then, the cells in each plate were cultured with an indicated concentration of ligustrazine $(0,10,20,30 \mu \mathrm{M})$ for different exposure times $(0,12,24,48 \mathrm{~h})$, respectively. After incubated with 10 $\mu \mathrm{L}$ CCK-8 solution per well, the cell viability was measured under a microplate reader (Bio-Rad, USA).

\section{DAPI staining}

SW480 and CT26 cells $\left(2 \times 10^{5}\right)$ were seeded in 6-well plates. After attachment, the cells were treated with an indicated concentration of ligustrazine $(0,10,20,30 \mu \mathrm{M})$ for $24 \mathrm{~h}$. The cells were washed and then fixed in $4 \%$ paraformaldehyde. The nuclei of cells of each plate were stained with DAPI for $5 \mathrm{~min}$, which was viewed under a fluorescence microscope (Nikon, Japan). 


\section{Cell apoptosis analysis}

SW480 and CT26 cells $\left(2 \times 10^{5}\right)$ were cultured in 6-well plates and allowed to attach. After treatment with an indicated concentration of ligustrazine $(0,10,20,30 \mu \mathrm{M})$ for $24 \mathrm{~h}$, the cells were harvested and washed with phosphate-buffered saline (PBS). Then, the cells were suspended with $100 \mu \mathrm{L}$ binding buffer and incubated with $5 \mu \mathrm{L}$ annexin V-FITC and $5 \mu \mathrm{L}$ 7-AAD for 10 min avoiding light. Cell apoptosis was measured under a flow cytometer (BD, USA). Moreover, PFT- $\alpha(10 \mathrm{mmol} / \mathrm{L})$ pretreated cells for $2 \mathrm{~h}$ were then treated with ligustrazine as above and the cell apoptosis was determined.

\section{Cell cycle analysis}

Different treated SW480 and CT26 cells were harvested, washed with PBS, and fixed in precooling $70 \%$ ethanol at $4{ }^{\circ} \mathrm{C}$ overnight. The next day, the cells were washed and suspended in $100 \mu \mathrm{L}$ PBS, then incubated with $50 \mu \mathrm{g} / \mathrm{mL}$ $\mathrm{PI}$ and $150 \mu \mathrm{g} / \mathrm{mL}$ RNase in the dark for $30 \mathrm{~min}$. Data were acquired under the flow cytometer (BD, USA).

\section{Western blot analysis}

Cell proteins were extracted by RIPA Protein Extraction Kit (Beyotime, China) according to the instructions. The extracted proteins were subjected to sodium dodecyl sulfatepolyacrylamide gel electrophoresis and transferred onto PVDF membranes. Then, the membranes were incubated with primary antibodies (p27, CDK2, cyclin D1, p53, Bax, Bcl-2, cleaved caspase- 3 , cleaved caspase- 9 and cleaved PARP) at $4{ }^{\circ} \mathrm{C}$ overnight, and then incubated with the second antibody $(1: 2,000)$ at $37^{\circ} \mathrm{C}$ for $1 \mathrm{~h}$. The blots were viewed under Chemiluminescence Imaging System (Bio$\mathrm{Rad}, \mathrm{USA}$ ) and the expression levels of the target proteins were analyzed by ImageLab Software.

\section{Quantitative real-time polymerase chain reaction (qRT- PCR) analysis}

Total cell RNAs were prepared with TRIzol reagent. The complementary DNA (cDNA) was determined using the First Strand cDNA Synthesis Kit. UltraSYBR One-Step RT-qPCR Kit was applied according to the protocol. The method of $2^{-\Delta \Delta \mathrm{Ct}}$ was conducted to measure the relative expression of mRNA. $\beta$-actin was served as the internal control.

\section{Statistical analysis}

All experiments were repeated three times. Data were expressed as the mean \pm SD for at least triple experiments and analyzed using the SPSS version 20.0. The statistical difference was determined using one-way ANOVA. And $\mathrm{P}<0.05$ and $\mathrm{P}<0.01$ were considered statistical significance.

\section{Results}

Ligustrazine suppressed proliferation in SW480 and CT26 cells

The natural herb, roots of the herb of Chuanxiong, and chemical structure of ligustrazine are presented in Figure $1 A, B, C$. The proliferative effects of ligustrazine at indicated concentrations $(0,10,20,30 \mu \mathrm{M})$ on CRC cells (SW480 and CT26) and CCD841 cell for different exposure times $(0,12,24,48 \mathrm{~h})$ were detected by CCK8 assay, respectively (Figure $1 D, E$ ). Compared with the control group, ligustrazine inhibited the proliferation of SW480 and CT26 cells in a dose- and time-dependent manner. The IC50 values of ligustrazine against SW480 and CT26 were $31.08 \pm 3.78$ and $32.16 \pm 5.74 \mu \mathrm{M}$ at $24 \mathrm{~h}$, respectively, as shown in Table 1. Besides, it showed that there was weak anti-proliferative ability in CCD841 cells. It also revealed that a high concentration of ligustrazine could significantly inhibit the cell proliferation activity of CRC cells.

\section{Ligustrazine induced apoptosis in SW480 and CT26 cells}

The bright filed graph of SW480 and CT26 cells after treatment with different concentrations of ligustrazine for $24 \mathrm{~h}$ were shown in Figure $2 A$. To further evaluate whether the anti-proliferative effects of ligustrazine caused by the induction of cell apoptosis, differently treated SW480 and CT26 cells were stained with DAPI, and the nuclei of each group were viewed, as presented in Figure $2 B$. The results showed a significant increase of the apoptotic cells in a ligustrazine-concentration dependent way, as evidenced by the condensed and fragmented nuclei. Consistently, flow cytometry assay showed that the SW480 and CT26 cells apoptosis were induced in a ligustrazine-dose dependent manner after treatment with different concentrations of ligustrazine for $24 \mathrm{~h}$ (Figure 2C,D). These findings indicated that the SW480 and CT26 cells apoptosis acted crucial roles in the anti-proliferative activity of ligustrazine on SW480 and CT26 cells. 
A

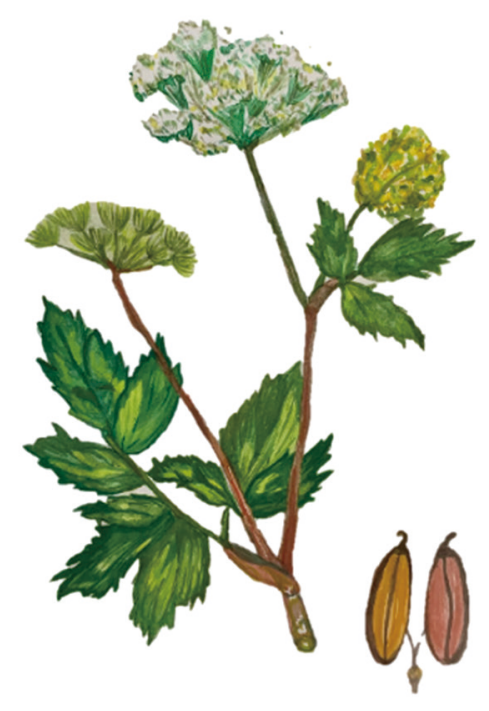

B

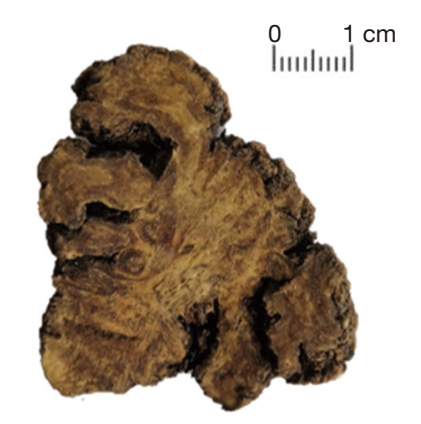

C

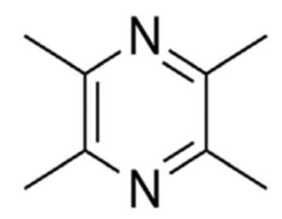

D

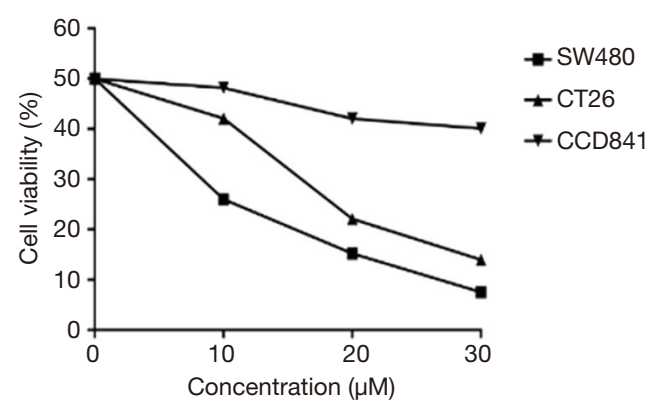

$\mathrm{E}$

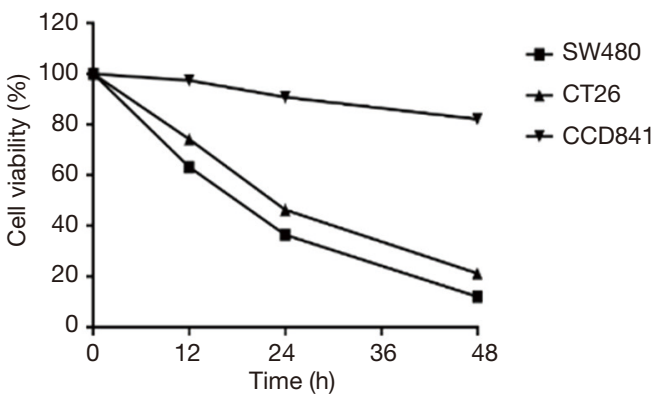

Figure 1 Ligustrazine suppressed the proliferation of SW480 and CT26 cells. (A) Natural herb of Chuanxiong. (B) Roots of herbal Chuanxiong. (C) Chemical structure of ligustrazine. (D,E) CCK-8 assay of SW480, CT26, and CCD841 cells treated with different concentrations of ligustrazine at different exposure time.

Table $1 \mathrm{IC}_{50}$ values of ligustrazine against SW480 and CT26 cells

\begin{tabular}{lccr}
\hline Cell lines & $12 \mathrm{~h}$ & $24 \mathrm{~h}$ & $48 \mathrm{~h}$ \\
\hline SW480 & $35.24 \pm 2.37$ & $31.08 \pm 3.78$ & $18.69 \pm 2.85$ \\
CT26 & $37.41 \pm 3.22$ & $32.16 \pm 5.74$ & $24.53 \pm 3.10$ \\
\hline
\end{tabular}

Note: the cells were cultured with different concentrations of ligustrazine for 12,24 , and $48 \mathrm{~h}$.

\section{Ligustrazine arrested cell cycle in SW480 and CT26 cells}

The cell cycle of SW480 and CT26 cells were also conducted by a flow cytometry assay. It showed that the cell cycle of ligustrazine-treated SW480 and CT 26 cells for $24 \mathrm{~h}$ was changed with a significant increase trend at the G0/G1 phase in comparison with the control group (Figure $3 A, B$ ). Furthermore, the levels of cell cycle-related protein expression were carried out by western blot after the SW480, and CT26 cells were treated with different concentrations of ligustrazine for $24 \mathrm{~h}$, respectively. It indicated that the protein expression levels of Cyclin D1 and CDK2 were decreased while the protein expression level of P27 was increased after different treatment with ligustrazine (Figure $4 A, B$ ). The results were consistent with those of qRT-PCR (Figure 4C). These findings suggested that ligustrazine could arrest CRC cell cycle distribution at the G0/G1 phase by regulating the cell cycle-related protein.

\section{Ligustrazine induced SW480 and CT26 cells apoptosis by activating mitochondrial-dependent patbway}

Mitochondrial dysfunction plays key roles in cellular proliferation and apoptosis regulation (12). In the process of apoptosis, a series of cascade reactions occur (13), during which many genes and pathways involved. To understand the mechanism of cell apoptosis induced by ligustrazine, the mitochondrial apoptosis-related protein was performed by western blot analysis. The SW480 and CT26 cells were treated with different concentrations of ligustrazine for $24 \mathrm{~h}$, respectively. The expression of $\mathrm{p} 53$, Bax, Bcl2 , cleaved caspase-3, cleaved caspase-9, and cleaved 


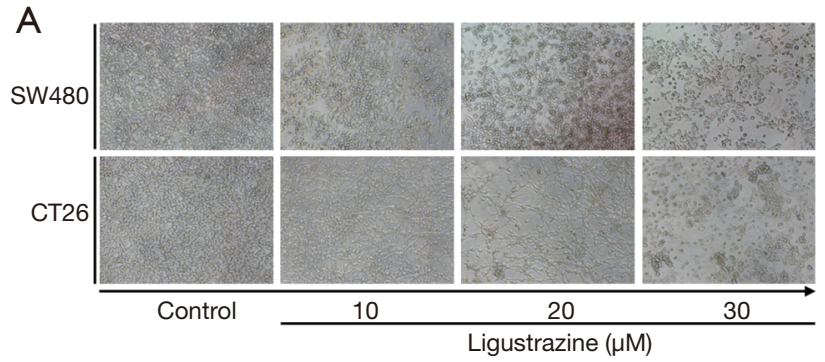

C
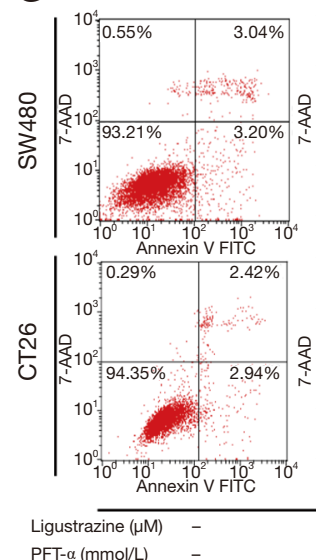
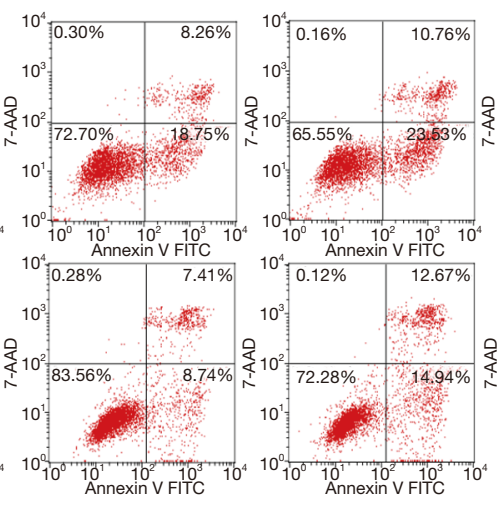

$\mathrm{PFT}-\alpha(\mathrm{mmol} / \mathrm{L})$
B

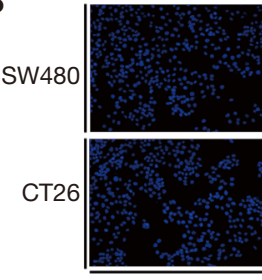

Control

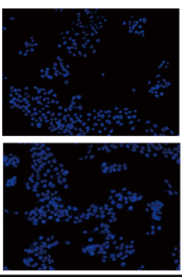

10
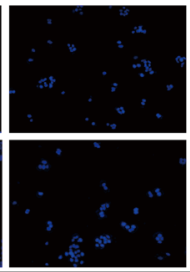

20 Ligustrazine $(\mu \mathrm{M})$

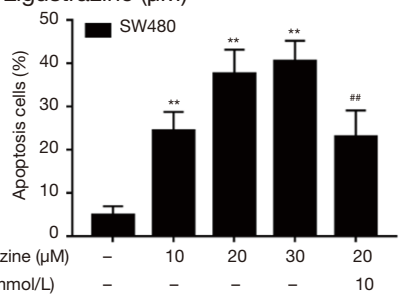

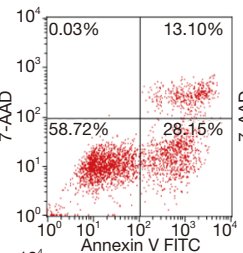

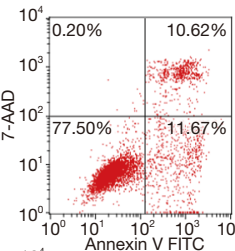

D

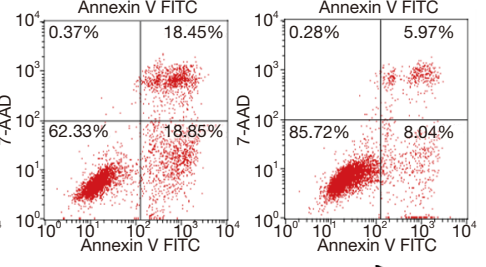

PFT $\alpha(\mathrm{mmol} / \mathrm{L})$

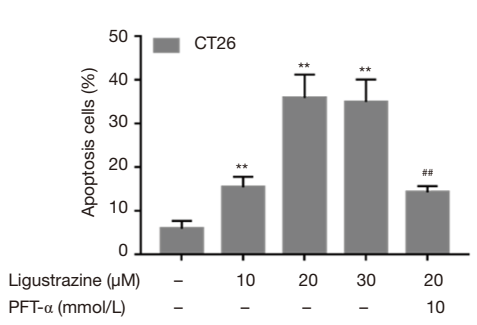

Figure 2 Ligustrazine induced the apoptosis of SW480 and CT26 cells. (A) The bright filed graph of SW480 and CT26 cells treated with ligustrazine at different concentrations $(\times 100)$. (B) DAPI staining assay of SW480 and CT26 cells treated with ligustrazine at different concentrations $(\times 100)$. (C,D) Flow cytometry analysis of cell apoptosis of different treated SW480 and CT26 cells. Significance: **, P<0.01 compared with the control group;, $\mathrm{P}<0.05$ and ${ }^{\# \#}, \mathrm{P}<0.01$ compared with the ligustrazine $(20 \mu \mathrm{M})$ group.

PARP were determined respectively. It demonstrated that ligustrazine dose-dependently increased the levels of P53 and Bax, and decreased the level of Bcl-2. Besides, the expression levels of cleaved caspase-3, cleaved caspase-9, and cleaved PARP were up-regulated after treatment with ligustrazine in a dose-dependent way (Figure $5 A, B$ ). The results were consistent with those of qRT-PCR (Figure 5C). Taken together, ligustrazine could promote SW480 and CT26 cells apoptosis by regulating the apoptosis-associated protein in an activated mitochondrial-dependent pathway.

\section{Ligustrazine-induced apoptosis was achieved by $p 53-$ dependent mitochondrial patbway and cell cycle arrest at the G0/G1 phase}

It is reported that the $\mathrm{p} 53$-mediated mitochondrial pathway plays pivotal biological functions in cell apoptosis (14). To further explore the critical role of $\mathrm{p} 53$ in ligustrazineinduced SW480 and CT26 cells apoptosis, PFT- $\alpha$, as a p53 inhibitor was applied to verify the hypothesis. After pre- treatment with or without PFT- $\alpha$ for $2 \mathrm{~h}$, the SW480 and CT26 cells were treated with $20 \mu \mathrm{M}$ ligustrazine for $24 \mathrm{~h}$, the above protein expressions were determined by western blot. It showed that the expression levels of apoptosisrelated protein were reversed by PFT- $\alpha$, as presented in Figure $6 A, B$. Furthermore, the flow cytometry assay indicated that PFT- $\alpha$ could effectively antagonize the cell apoptosis and cell cycle arrest induced by ligustrazine (Figure 2C,D and Figure 3A,B). Collectively, the results suggested that the ligustrazine-induced SW480 and CT26 cells apoptosis were mediated by p53-dependent mitochondrial pathway and cell cycle arrest at the G0/G1 phase.

\section{Discussion}

Cell apoptosis is a crucial pathological process, which is closely related to the occurrence, development, and prognosis of tumors $(15,16)$. It is an important field to study the underlying mechanisms of anti-tumor efficacy. 

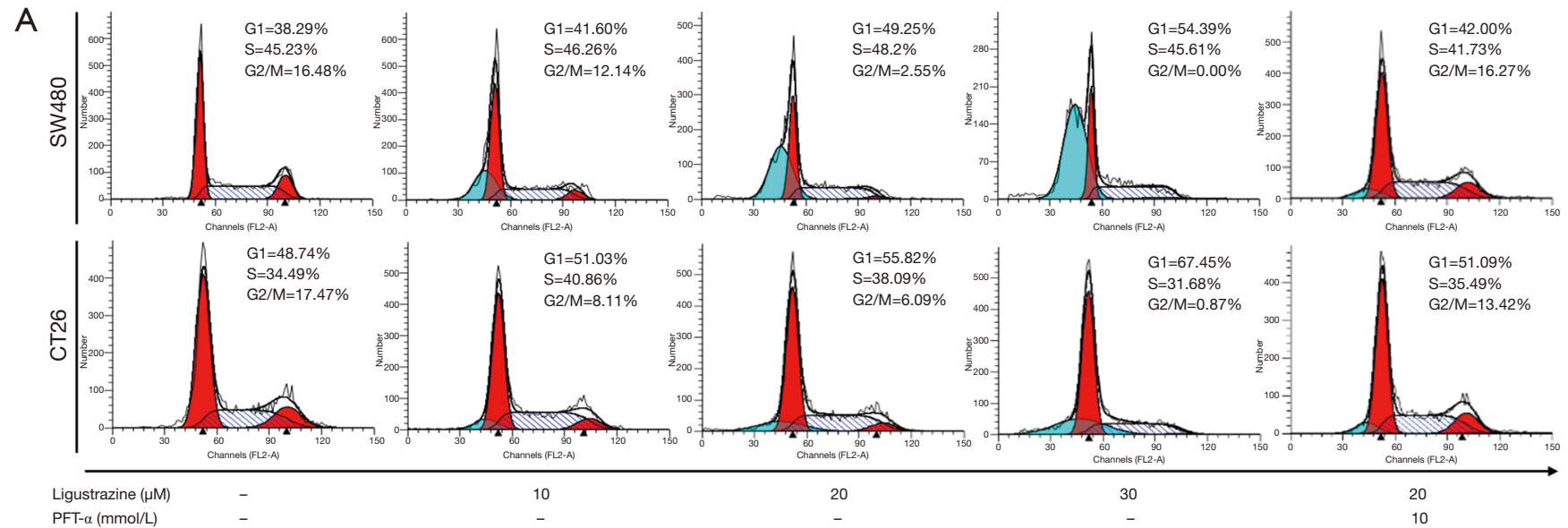

10

20

30

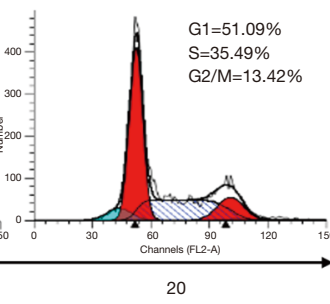

B
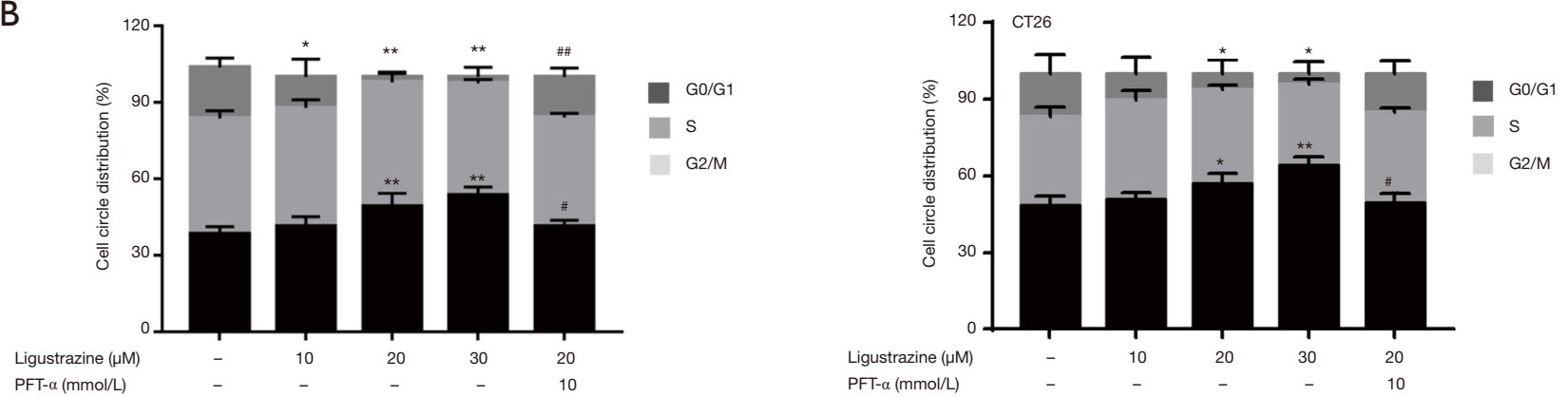

Figure 3 Ligustrazine arrested the cell cycle of SW480 and CT26 cells. (A,B) Flow cytometry analysis of cell cycle of different treated SW480 and CT26 cells. Significance: *, P<0.05 and ${ }^{* *}, \mathrm{P}<0.01$ compared with the control group; ${ }^{\#}, \mathrm{P}<0.05$ and ${ }^{\# \#,} \mathrm{P}<0.01$ compared with the ligustrazine $(20 \mu \mathrm{M})$ group.

Mounting studies have focused on various drugs to induce cell apoptosis in the treatment of various cancers. Although some studies have achieved great improvement, some issues especially the side effects cannot be ignored (17). A variety of herbal extraction with remarkable anticancer efficacy and lower toxicity i.e., ligustrazine have received heightened attention on its antioxidant and antitumor activity. Increasing evidence has reported that ligustrazine possess the bioactivities of cell apoptosis induction and cell differentiation through a variety of regulatory mechanism (18-20). However, the critical mechanism of ligustrazine on CRC cells is still unknown. In this study, we first uncovered the underlying pathogenesis of ligustrazine on CRC at the cellular level.

We first found that the proliferative ability of SW480 and CT26 cells were significantly inhibited by ligustrazine in a time- and dose-dependent manner. It indicated that the inhibitory effect of ligustrazine on cell proliferation was a positive correlation to the concentration and treatment time. The findings demonstrated that ligustrazine had significant anti-tumor activity, which was consistent with previous studies (21-23).

Proliferation and apoptosis of tumor cells are closely related to the regulation of the cell cycle, and tumor cell cycle arrest is an important indicator to evaluate the effect of anti-tumor therapy (24). In the current study, we found that ligustrazine could restrict cell proliferation by arresting cells at the G0/G1 phase. It demonstrated that ligustrazine might function on SW480 and CT26 cells at the G0/G1 phase, and make some cells at the stage of stagnation, thereby inhibiting the proliferation of SW480 and CT26 cells. The cell cycle is divided into four stages, that is, G1, S, G2, and M. These four stages are regulated by a panel of important modulators, such as Cyclin D1, CDK2, and p27 (25). Cyclin-CDK complexes, which are closely associated with the G1 phase in the progress of cell cycle, are downregulated; and p27 as the CDK inhibitory gene is upregulated for accelerating cell cycle arrest (26). 

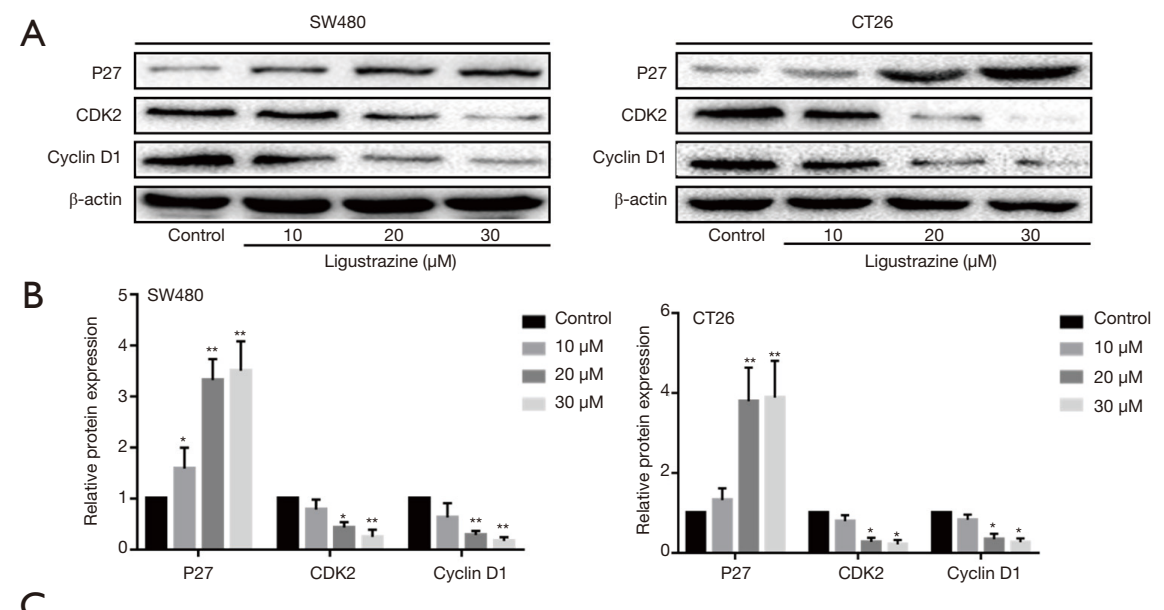

C
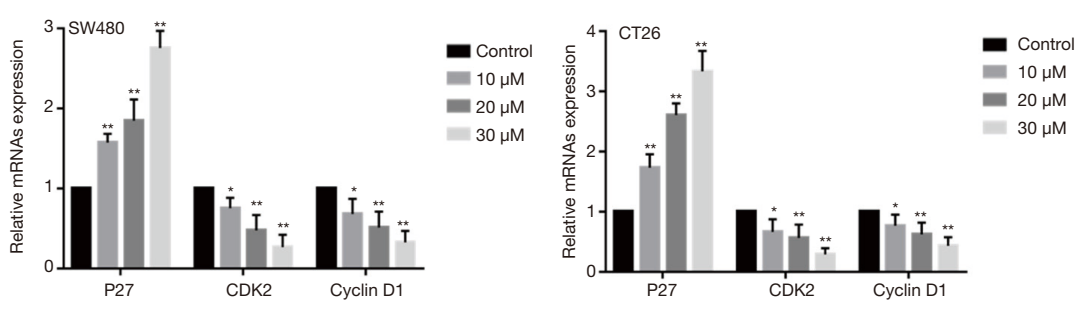

Figure 4 Ligustrazine regulated the cell cycle-related protein levels of SW480 and CT26 cells. (A,B) Western blot analysis of the cell cyclerelated protein expressions. (C) Quantitative analysis of the cell cycle-related protein levels. Significance: * $\mathrm{P}<0.05$ and ${ }^{* *}, \mathrm{P}<0.01$.

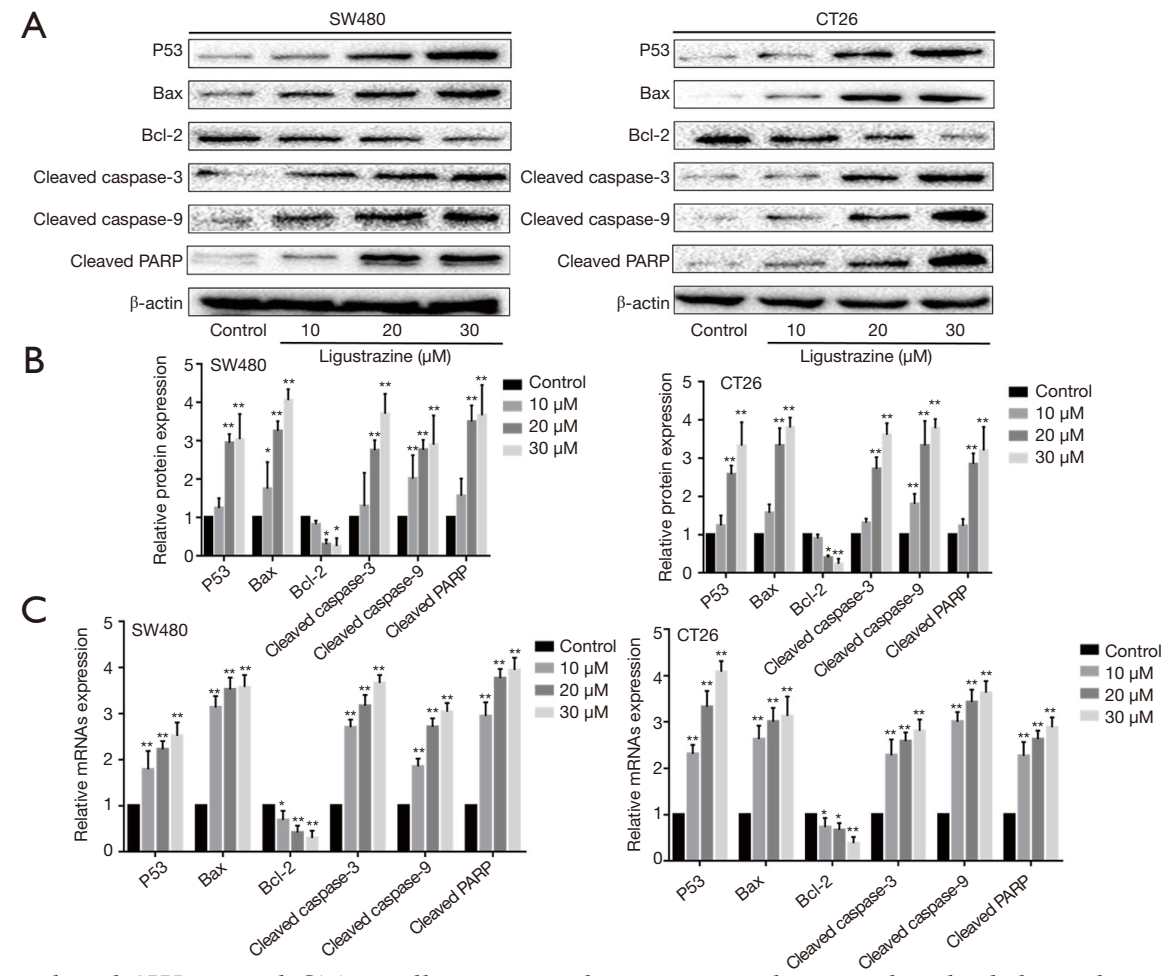

Figure 5 Ligustrazine induced SW480 and CT26 cells apoptosis by activating the mitochondrial-dependent pathway. (A,B) Western blot analysis of the cell apoptosis-associated protein expressions. (C) Quantitative analysis of the cell apoptosis-associated protein levels. Significance: *, $\mathrm{P}<0.05$ and ${ }^{* *}, \mathrm{P}<0.01$. 
A

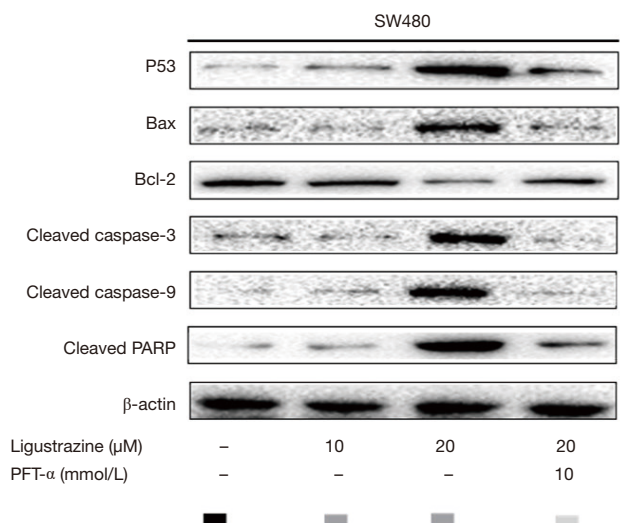

B

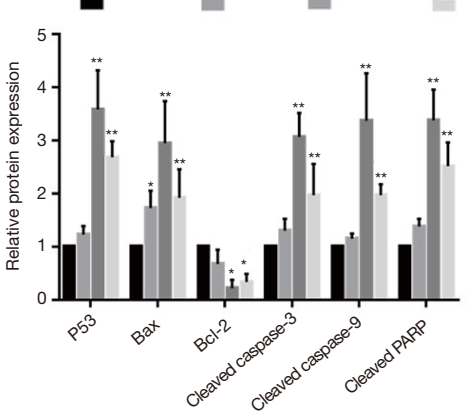

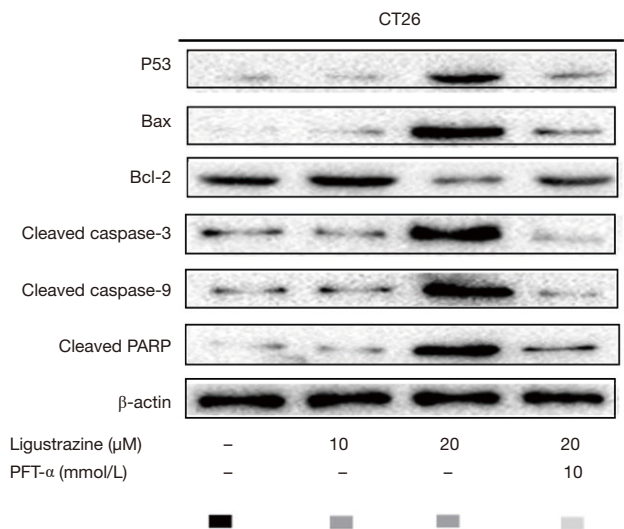

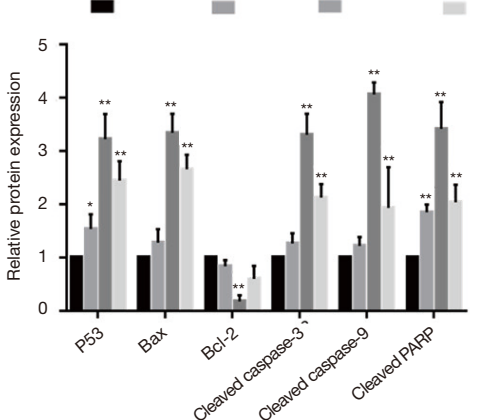

Figure 6 Ligustrazine-induced apoptosis was achieved via p53-dependent mitochondrial pathway and cell cycle arrest at the G0/G1 phase. $(A, B)$ Western blot analysis of the protein expressions of SW480 and CT26 cells with different treatments.

Currently, our results showed that ligustrazine could induce cell apoptosis through promoting G0/G1 phase arrest by regulating the expression levels of cell cycle-related proteins, which indicated that special anti-tumor effects of ligustrazine on SW480 and CT26 cells growth.

Cell apoptosis is a cell death-related progress, which is regulated by the p53 signal pathway (27). P53 is an important tumor suppressor gene, and it is also the most commonly mutated gene in human malignant tumors $(28,29)$. A substantial amount of evidence has shown that p53 is related to a variety of malignant tumors, including liver, gastric, and pancreatic cancer. And $\mathrm{p} 53$ plays a key role in the regulation of cell cycle, DNA repair, and apoptosis induction (30-32). Thus, p53 might become a crucial target of tumor therapy. The p53-mediated cell death is mainly mediated by the mitochondrial-regulated pathway via regulating expressions of the apoptosis-associated family members, such as Bcl-2 and Bax (14). Bax is a pro-apoptotic protein belonging to the Bcl-2 family; it can inhibit the activity of Bcl-2 and form a heterodimer with Bcl-2, a kind of anti-apoptotic protein, leading to the dysfunction of mitochondrial (33). Then, a series of caspases are activated and cleaved-caspases are generated following the triggered apoptotic pathway. The caspase proteins family play crucial roles in caspase cascade. Caspase-9 is the promotor in the caspase cascade, which can activate the apoptotic effectors, i.e., caspase- 3 and PARP. The activated cascade reaction eventually leads to cell death. In our study, we found that ligustrazine up-regulated $\mathrm{p} 53$ and pro-apoptotic protein expression levels, and down-regulated the anti-apoptotic protein expression levels. The results were confirmed by p53 inhibitor assays. All the above evidence indicated that ligustrazine might induce SW480 and CT26 cells apoptosis mainly via the $\mathrm{p} 53$-dependent mitochondrial apoptotic pathway.

To conclude, our findings revealed that ligustrazine could inhibit the proliferation of SW480 and CT26 cells by changing the cell cycle distribution, which leads to cell cycle arrest at the G0/G1 phase. Besides, ligustrazine could promote the expression of $\mathrm{p} 53$ protein and regulate relative apoptotic protein expression, resulting in cell apoptosis via the mitochondrial pathway (Figure 7). The evidence suggested that ligustrazine might serve as a potential antitumor agent. 


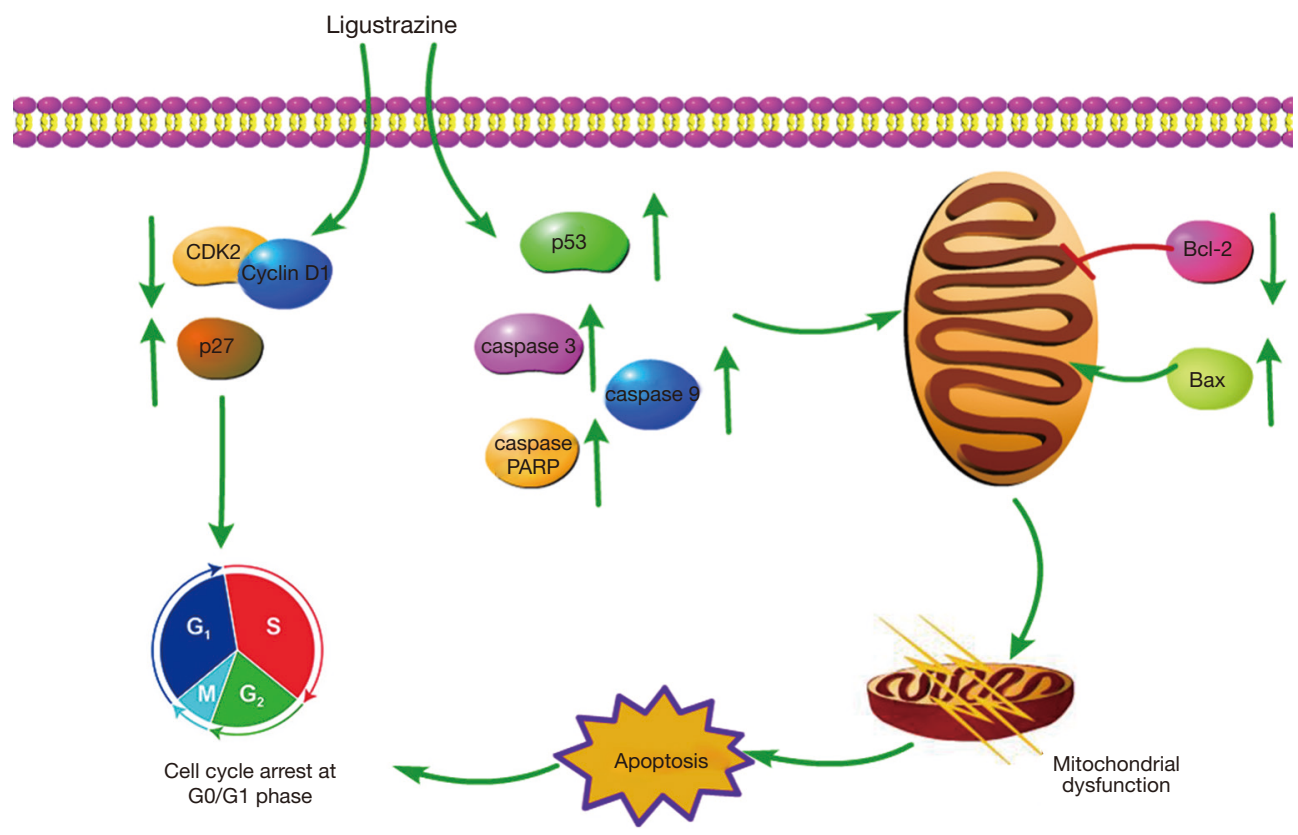

Figure 7 Ligustrazine promoted the SW480 and CT26 cells apoptosis via a p53-dependent mitochondrial pathway and arrested the cell cycle at the G0/G1 phase.

\section{Acknowledgments}

Funding: This work was supported by the National Natural Science Foundation of China (No. 81704084, 81673982 and 81603529), the Natural Science Foundation of the Jiangsu Higher Education Institutions (No. 16KJB360002), the advantages of nursing discipline project of Jiangsu Province (No. 2019YSHL005), the Priority Academic Program Development of Jiangsu Higher Education Institutions (PAPD), the Open Projects of the Discipline of Chinese Medicine of Nanjing University of Chinese Medicine (ZYX03KF63), the Jiangsu Government Scholarship for Overseas Studies, China Scholarship Council and Qing Lan Project.

\section{Footnote}

Reporting Checklist: The authors have completed the MDAR checklist. Available at http://dx.doi.org/10.21037/ apm-20-288

Data Sharing Statement: Available at http://dx.doi. org/10.21037/apm-20-288

Conflicts of Interest: All authors have completed the ICMJE uniform disclosure form (available at http://dx.doi. org/10.21037/apm-20-288). The authors have no conflicts of interest to declare.

Ethical Statement: The authors are accountable for all aspects of the work in ensuring that questions related to the accuracy or integrity of any part of the work are appropriately investigated and resolved.

Open Access Statement: This is an Open Access article distributed in accordance with the Creative Commons Attribution-NonCommercial-NoDerivs 4.0 International License (CC BY-NC-ND 4.0), which permits the noncommercial replication and distribution of the article with the strict proviso that no changes or edits are made and the original work is properly cited (including links to both the formal publication through the relevant DOI and the license). See: https://creativecommons.org/licenses/by-nc-nd/4.0/.

\section{References}

1. Fitzmaurice C, Dicker D, Pain A, et al. The Global Burden of Cancer 2013. JAMA Oncol 2015;1:505-27.

2. Arnold M, Sierra MS, Laversanne M, et al. Global patterns and trends in colorectal cancer incidence and mortality. GUT 2017;66:683-91. 
3. Lawler M, Alsina D, Adams RA, et al. Critical research gaps and recommendations to inform research prioritisation for more effective prevention and improved outcomes in colorectal cancer. GUT 2018;67:179-93.

4. Li Y, Qin X, Li P, et al. Isobavachalcone isolated from Psoralea corylifolia inhibits cell proliferation and induces apoptosis via inhibiting the AKT/GSK-3beta/beta-catenin pathway in colorectal cancer cells. Drug Des Devel Ther 2019;13:1449-60.

5. Lv J, Jia Y, Li J, et al. Gegen Qinlian decoction enhances the effect of PD-1 blockade in colorectal cancer with microsatellite stability by remodelling the gut microbiota and the tumour microenvironment. Cell Death Dis 2019;10:415.

6. Tao Y, Zhan S, Wang Y, et al. Baicalin, the major component of traditional Chinese medicine Scutellaria baicalensis induces colon cancer cell apoptosis through inhibition of oncomiRNAs. Sci Rep 2018;8:14477.

7. Pan J, Shang JF, Jiang GQ, et al. Ligustrazine induces apoptosis of breast cancer cells in vitro and in vivo. $\mathrm{J}$ Cancer Res Ther 2015;11:454-58.

8. Cheng L, Ma H, Shao M, et al. Synthesis of folatechitosan nanoparticles loaded with ligustrazine to target folate receptor positive cancer cells. Mol Med Rep 2017;16:1101-08.

9. Yin J, Yu C, Yang Z, et al. Tetramethylpyrazine inhibits migration of SKOV3 human ovarian carcinoma cells and decreases the expression of interleukin- 8 via the ERK1/2, p38 and AP-1 signaling pathways. Oncol Rep 2011;26:671-9.

10. Chen L, Lu Y, Wu JM, et al. Ligustrazine inhibits B16F10 melanoma metastasis and suppresses angiogenesis induced by Vascular Endothelial Growth Factor. Biochem Biophys Res Commun 2009;386:374-9.

11. LaCasse EC, Mahoney DJ, Cheung HH, et al. IAPtargeted therapies for cancer. Oncogene 2008;27:6252-75.

12. Zhang Y, Sun C, Xiao G, et al. Host defense peptide Hymenochirin-1B induces lung cancer cell apoptosis and cell cycle arrest through the mitochondrial pathway. Biochem Biophys Res Commun 2019;512:269-75.

13. Zhao N, Tian KT, Cheng KG, et al. Antiproliferative activity and apoptosis inducing effects of nitric oxide donating derivatives of evodiamine. Bioorg Med Chem 2016;24:2971-8

14. Zhou S, Wen H, Li H. Magnolol induces apoptosis in osteosarcoma cells via G0/G1 phase arrest and p53mediated mitochondrial pathway. J Cell Biochem 2019;120:17067-79.
15. Chen SH, Forrester W, Lahav G. Schedule-dependent interaction between anticancer treatments. Science 2016;351:1204-8.

16. Xie Y, Song J, Zong Q, et al. Decreased Expression of MIR-134 and its Clinical Significance in Human Colorectal Cancer. Hepatogastroenterology 2015;62:615-9.

17. Riedl S, Zweytick D, Lohner K. Membrane-active host defense peptides--challenges and perspectives for the development of novel anticancer drugs. Chem Phys Lipids 2011;164:766-81.

18. Zou L, Liu X, Li J, et al. Tetramethylpyrazine Enhances the Antitumor Effect of Paclitaxel by Inhibiting Angiogenesis and Inducing Apoptosis. Front Pharmacol 2019;10:707.

19. Shen J, Zeng L, Pan L, et al. Tetramethylpyrazine regulates breast cancer cell viability, migration, invasion and apoptosis by affecting the activity of Akt and caspase-3. Oncol Lett 2018;15:4557-63.

20. Chen Z, Pan X, Georgakilas AG, et al. Tetramethylpyrazine (TMP) protects cerebral neurocytes and inhibits glioma by down regulating chemokine receptor CXCR4 expression. Cancer Lett 2013;336:281-9.

21. Huang HH, Liu FB, Ruan Z, et al. Tetramethylpyrazine (TMPZ) triggers S-phase arrest and mitochondriadependent apoptosis in lung cancer cells. Neoplasma 2018;65:367-75.

22. Wang H, Zhang W, Cheng Y, et al. Design, Synthesis and Biological Evaluation of Ligustrazine-Flavonoid Derivatives as Potential Anti-Tumor Agents. Molecules 2018;23:2187.

23. Chen H, Cao J, Zhu Z, et al. A Novel Tetramethylpyrazine Derivative Protects Against Glutamate-Induced Cytotoxicity Through PGC1alpha/Nrf2 and PI3K/Akt Signaling Pathways. Front Neurosci 2018;12:567.

24. Liu Y, Cao Y, Zhang W, et al. A small-molecule inhibitor of glucose transporter 1 downregulates glycolysis, induces cell-cycle arrest, and inhibits cancer cell growth in vitro and in vivo. Mol Cancer Ther 2012;11:1672-82.

25. Mills CC, Kolb EA, Sampson VB. Development of Chemotherapy with Cell-Cycle Inhibitors for Adult and Pediatric Cancer Therapy. Cancer Res 2018;78:320-5.

26. Hunter T, Pines J. Cyclins and cancer. II: Cyclin D and CDK inhibitors come of age. Cell 1994;79:573-82.

27. Amaral JD, Xavier JM, Steer CJ, et al. Targeting the p53 pathway of apoptosis. Curr Pharm Des 2010;16:2493-503.

28. Kotake Y, Kitagawa K, Ohhata T, et al. Long Non- 
coding RNA, PANDA, Contributes to the Stabilization of p53 Tumor Suppressor Protein. Anticancer Res 2016;36:1605-11.

29. Lee MH, Thomas JL, Chen JZ, et al. Activation of tumor suppressor $\mathrm{p} 53$ gene expression by magnetic thymineimprinted chitosan nanoparticles. Chem Commun (Camb) 2016;52:2137-40.

30. Fei Q, Shang K, Zhang J, et al. Histone methyltransferase SETDB1 regulates liver cancer cell growth through methylation of p53. Nat Commun 2015;6:8651.

31. Waraya M, Yamashita K, Ema A, et al. Exclusive Association of p53 Mutation with Super-High Methylation of Tumor Suppressor Genes in the p53 Pathway in a Unique Gastric Cancer Phenotype. PLoS One 2015;10:e0139902.

32. Batchu RB, Gruzdyn OV, Qazi AM, et al. Enhanced phosphorylation of p53 by microRNA-26a leading to growth inhibition of pancreatic cancer. Surgery 2015;158:981-86, 986-87.

33. Dolka I, Krol M, Sapierzynski R. Evaluation of apoptosisassociated protein (Bcl-2, Bax, cleaved caspase-3 and p53) expression in canine mammary tumors: An immunohistochemical and prognostic study. Res Vet Sci 2016;105:124-33.

Cite this article as: Bian Y, Yang L, Sheng W, Li Z, Xu Y, Li W, Zeng L. Ligustrazine induces the colorectal cancer cells apoptosis via p53-dependent mitochondrial pathway and cell cycle arrest at the G0/G1 phase. Ann Palliat Med 2021;10(2):15781588. doi: 10.21037/apm-20-288 